\title{
Herança da Resistência ao Watermelon mosaic virus em Melancia (Citrullus lanatus L.)*
}

\author{
J. Evando A. Beserra Júnior ${ }^{1}$, Wilson R. Maluf ${ }^{2}$,Antonia R. Figueira ${ }^{1}$, Beatriz M. Barguil ${ }^{1}$ \\ ${ }^{1}$ Departamento de Fitopatologia; ${ }^{2}$ Departamento de Agricultura, Universidade Federal de Lavras, \\ Cx. Postal 3037, CEP 37200-000, Lavras, MG, e-mail: antonia@ufla.br
}

(Aceito para publicação em 10/05/2006)

Autor para correspondência: Antonia R. Figueira

BESERRA JR, J.E. A., MALUF, W.R., FIGUEIRA, A.R. \& BARGUIL, B.M. Herança da resistência ao Watermelon mosaic virus em melancia (Citrullus lanatus L.). Fitopatologia Brasileira 31:302-305. 2006

\section{RESUMO}

Foi estudado o controle genético da resistência do genótipo não-comercial de melancia, PI 595201, ao vírus do mosaico da melancia (Watermelon mosaic virus, WMV). Avaliaram-se os genitores, a cultivar Crimson Sweet $\left(\mathrm{P}_{1}\right.$ suscetível) e a introdução PI 595201 ( $\mathrm{P}_{2}$ - resistente), bem como as populações $\mathrm{F}_{1}, \mathrm{~F}_{2}$, e os retrocruzamentos para ambos os parentais, $\mathrm{RC}_{11}\left(\mathrm{~F}_{1} \times \mathrm{P}_{1}\right)$ e $\mathrm{RC}_{12}\left(\mathrm{~F}_{1} \times \mathrm{P}_{2}\right)$. A severidade dos sintomas, depois da inoculação mecânica com WMV, foi avaliada de acordo com uma escala de notas de 1 (folhas sem sintomas) a 5 (mosaico intenso e deformações foliares). A cultivar Crimson Sweet apresentou média geral acima de 4,0, enquanto a introdução PI 595201 apresentou média 1,0, confirmando a reação contrastante das linhagens parentais. A hipótese de herança monogênica foi rejeitada, mostrando ser a resistência da introdução PI 595201 de controle oligo ou poligênico, com indicativo de dominância completa no sentido de maior resistência ao vírus. A estimativa de herdabilidade no sentido amplo foi acima de 0,8 . A estimativa do número de genes, controlando o caráter, foi 4,16. O modelo aditivo-dominante é sugerido para explicar o controle genético da resistência.

Palavras-chave adicionais: Controle genético, Cucurbitaceae, herdabilidade, oligogenes, Potyvirus.

\begin{abstract}
Inheritance of resistance to Watermelon mosaic virus in watermelon (Citrullus lanatus $\mathbf{L}$.

The genetic control of resistance of the non-commercial watermelon accession PI 595201 to the Watermelon mosaic virus (WMV) was studied. Parental lines Crimson Sweet $\left(\mathrm{P}_{1}\right.$ - susceptible parent) and PI 595201 ( $\mathrm{P}_{2}-$ resistant parent), generations $\mathrm{F}_{1}, \mathrm{~F}_{2}$ and backcrosses to both parents were tested. Symptom severity after mechanical inoculation with WMV was rated on a scale from 1 (no symptoms) to 5 (intense mosaic and foliar distortion). Crimson Sweet had a mean value of 4.0, whereas PI 595201 had a mean value of 1.0, demonstrating the contrasting reaction of these lines for WMV resistance. The heritability estimates were $>0.8$, indicating that genetic gains from selection are feasible. The additive-dominance model was suggested to explain resistance inheritance. The hypothesis of monogenic control of WMV resistance in watermelon was rejected with an indication that the resistance of PI 595201 is under oligo or polygenic control, possibly by complete dominance in the direction of higher levels of resistance. The estimated number of genes that control WMV resistance was 4.16.
\end{abstract}

Additional keywords: genetic control, Cucurbitaceae, heritability, oligogenes, Potyvirus.

As espécies de vírus do gênero Potyvirus são consideradas fatores limitantes no cultivo de cucurbitáceas nas principais regiões produtoras do Brasil, em razão do elevado número de espécies de afídeos vetores e, também, do grande número de espécies hospedeiras conhecidas, como aquelas da família Cucurbitaceae (Zerbini \& MacielZambolim, 2000). Dentre os vírus já relatados capazes de infectar plantas de melancia no Brasil, maior atenção tem sido dada ao vírus da mancha anelar do mamoeiro - estirpe melancia (Papaya ringspot virus - watermelon strain, PRSV-W), família Potyviridae, gênero Potyvirus, por se tratar do vírus predominante em diversas regiões produtoras

*Parte da Dissertação de Mestrado do primeiro autor. Universidade Federal de Lavras. 2004. de cucurbitáceas no País (Moura et al., 2001; Ramos et al., 2003). Entretanto, nos últimos anos, o vírus do mosaico da melancia (Watermelon mosaic virus, WMV), família Potyviridae, gênero Potyvirus, tem causado prejuízos significativos à produção dessa olerícola (Cruz et al., 1999; Yuki et al., 2000).

O WMV possui ampla gama de hospedeiras, infectando cerca de 178 espécies de plantas dentro de 27 famílias, incluindo cucurbitáceas e algumas espécies de leguminosas, malváceas, quenopodiáceas e ornamentais (Shukla et al., 1994). Plantas infectadas exibem sintomas de mosqueado, mosaico, bolhosidades e deformações do limbo foliar. A qualidade e a quantidade de produção dos frutos podem ser reduzidas (Oliveira et al., 2000). A disseminação do vírus no campo é realizada com muita eficiência por 
mais de 38 espécies de afídeos em 19 gêneros de maneira não-persistente, sendo seus principais vetores Myzus persicae Sulzer, 1776 e Aphis spp. (Fauquet et al., 2005). Por esse motivo, o controle químico dos insetos vetores não apresenta resultados satisfatórios no combate a doença. Conseqüentemente, a forma de controle mais eficiente consiste em desenvolver cultivares resistentes, mediante introdução de genes capazes de conferir resistência em cultivares comerciais suscetíveis.

Há alguns anos o United States Department of Agriculture (USDA) disponibilizou vários acessos de germoplasma de melancia resistentes ao WMV (Cucurbit Genetics Cooperative, 1996), mas o modo de herança dessa resistência não foi indicado.

Diante do quadro de escassez de cultivares de melancia resistentes ao WMV, o presente trabalho objetivou determinar o modo de herança da resistência de melancia a esse vírus em uma das introduções obtidas do USDA, bem como estimar os parâmetros genéticos nas populações segregantes.

\section{Linhagens parentais e cruzamentos}

Com o objetivo de evitar a disseminação do isolado viral na região, o experimento foi realizado inteiramente em casa de vegetação, durante o primeiro semestre de 2003. As cultivares Crimson Sweet e PI 595201 foram usadas para obtenção da geração $\mathrm{F}_{1}$. Crimson Sweet é uma das cultivares de Citrullus lanatus L. mais cultivadas no Brasil e suscetível a viroses, enquanto que PI 595201 é uma introdução nãocomercial obtida do USDA (US Vegetable Laboratory, Charleston, USA) e anunciada como resistente ao WMV (Cucurbit Genetics Cooperative, 1996).

As plantas da geração $F_{1}$ (Crimson Sweet $x$ PI 595201) foram obtidas por polinizações controladas. Após autofecundação manual de $\mathrm{F}_{1}$, foram obtidas plantas de $\mathrm{F}_{2}$, e simultaneamente, as gerações de retrocruzamentos através do cruzamento de $F_{1}$ com Crimson Sweet $\left(\mathrm{RC}_{11}=\mathrm{F}_{1}\right.$ x $\left.\mathrm{P}_{1}\right)$, e do cruzamento de $\mathrm{F}_{1}$ com PI $595201\left(\mathrm{RC}_{12}=\mathrm{F}_{1} \mathrm{x}\right.$ $\mathrm{P}_{2}$ ). O delineamento experimental utilizado foi o de blocos casualizados com quatro repetições. Cada bloco consistiu de 12 plantas da população $\mathrm{P}_{1}$ (Crimson Sweet), 12 da $\mathrm{P}_{2}$ (PI 595201), 18 da $\mathrm{F}_{1}, 52$ de $\mathrm{F}_{2}, 28$ de $\mathrm{RC}_{11}$ e 28 da $\mathrm{RC}_{12}$, de modo que os números totais de plantas utilizadas foram 48 , $48,72,208,112$ e 112 respetivamente para $\mathrm{P}_{1}, \mathrm{P}_{2}, \mathrm{~F}_{1}, \mathrm{~F}_{2}$, $\mathrm{RC}_{11}$ e $\mathrm{RC}_{12}$.

\section{Inoculações e avaliação da severidade da doença}

$\mathrm{O}$ isolado viral utilizado nesse experimento foi obtido em campos de produção de melancia no Estado de Pernambuco e caracterizado como WMV. Folhas jovens de Cucurbita pepo L. cv. Caserta, previamente inoculadas com WMV, apresentando sintomas de mosaico severo foram usadas na inoculação. As folhas foram maceradas com auxílio de $\mathrm{N}_{2}$ líquido e posterior adição de tampão fosfato de potássio $0,01 \mathrm{M}, \mathrm{pH} 7,0$ e $0,1 \%$ de sulfito de sódio, na proporção de 1 grama de tecido foliar fresco para $5 \mathrm{mLde}$ tampão (p/v). A inoculação foi realizada por fricção da suspensão viral sobre as folhas cotiledonares previamente polvilhadas com o abrasivo carborundum 400 mesh.

Foram realizadas quatro inoculações, para evitar a ocorrência de escape, sendo a primeira no estádio de folhas cotiledonares expandidas e as subseqüentes, em intervalos de 2 dias. As plantas foram avaliadas de acordo com a severidade dos sintomas aos 35, 42 e 49 dias após a primeira inoculação. As plantas foram avaliadas individualmente, pelo mesmo operador, quanto à reação sintomatológica ao WMV. Um sistema de escala de notas, semelhante ao utilizado por Maluf et al. (1997) para PRSV-W em Cucurbita maxima Duchesne foi adotado na classificação da severidade dos sintomas:

$1=$ Folhas sem sintomas.

$2=$ Poucas folhas com leve mosaico nos bordos.

3 = Maioria das folhas com mosaico; poucas bolhas.

$4=$ Maioria das folhas com mosaico; muitas bolhas e/ou folhas com leves deformações.

5 = Mosaico intenso e folhas com deformações severas.

Estimativa dos parâmetros genéticos e fenotípicos

Médias e variâncias obtidas a partir dos sintomas exibidos pelas populações $\mathrm{P}_{1}, \mathrm{P}_{2}, \mathrm{~F}_{1}, \mathrm{~F}_{2}, \mathrm{RC}_{11}$ e $\mathrm{RC}_{12}$ foram utilizadas para a obtenção das estimativas das variâncias: genética $\left(\hat{\sigma}_{\mathrm{G}}^{2}\right)$, ambiental $\left(\hat{\sigma}_{\mathrm{E}}^{2}\right)$, fenotípica $\left(\hat{\sigma}_{\mathrm{F} 2}^{2}\right)$, aditiva $\left(\hat{\sigma}_{\mathrm{A}}^{2}\right)$, de dominância ( $\hat{\sigma}_{\mathrm{A}}^{2}$ ), das herdabilidades no sentido amplo $\left(\mathrm{h}_{\mathrm{a}}^{2}\right)$ e restrito $\left(\mathrm{h}_{\mathrm{r}}^{2}\right)$.

Os efeitos aditivos [a] e não aditivos [d] do(s) gene(s) que controla $(\mathrm{m})$ o caráter foram estimados a partir das médias das gerações, pelo método dos quadrados mínimos ponderados (Mather \& Jinks, 1977), por meio do programa Mapgen v. 3.0. Também foram estimados o grau médio de dominância (GMD) e o número mínimo de genes (ๆ) envolvidos na expressão do caráter de acordo com Wright (1934).

Os dados foram usados para testar a hipótese de herança monogênica sob diferentes graus médios de dominância presumidos, como descrito por Oliveira et al., (2003).

\section{Teste de modelos genéticos por meio da função de máxima verossimilhança}

Para testar a hipótese de herança monogênica e/ou a presença de loci poligênicos (ou modificadores) afetando o caráter, foi utilizada uma metodologia alternativa, proposta por Silva (2003), baseada em estimadores de máxima verossimilhança. O modelo mais geral é aquele que apresenta a existência de um gene de efeito maior, juntamente com poligenes com efeitos aditivos e de dominância e variâncias ambientais iguais em todas as gerações. Admitiram-se, ainda, genes independentes (tanto poligenes, como de efeito maior). A partir das funções de verossimilhança para cada modelo, foi possível compor testes de interesse, considerando diferentes hipóteses. Os testes foram realizados utilizando o software estatístico "Monogen v. 0.1". 
As plantas obtidas do retrocruzamento $\mathrm{P}_{1} \times \mathrm{F}_{1}\left(\mathrm{RC}_{11}\right)$ apresentaram características inerentes do parental recorrente, como tempo mais curto de germinação das sementes e tonalidade semelhante da cor das folhas. Características contrárias foram observadas nas plantas $\mathrm{RC}_{12}$. Aos 35 dias após a primeira inoculação, a cultivar Crimson Sweet apresentou notas elevadas com média superior a 4,0, a introdução PI 595201 apresentou média 1,0, enquanto as plantas das populações $\mathrm{F}_{1}$ e $\mathrm{RC}_{11}$ apresentaram médias de 2,43 e 2,50, respectivamente, e as populações $F_{2}$ e $R_{12}$ apresentaram médias de 1,97 e 1,43, respectivamente, evidenciando a resistência da introdução PI 595201 ao WMV. As médias das notas nas três avaliações foram semelhantes, não havendo progressão no nível de sintomas ao longo do tempo. Por essa razão somente os dados referentes à primeira avaliação são apresentados.

Embora o mecanismo de resistência da introdução PI 595201 não seja conhecido, podendo interferir com a multiplicação e/ou translocação viral célula-a-célula, somente $30 \%$ das plantas de Cucurbita pepo cv. Caserta exibiram sintomas quando retroinoculadas a partir de PI 595201, ao passo que $100 \%$ das plantas manifestaram sintomas quando retroinoculadas a partir de Crimson Sweet.

A estimativa de herdabilidade no sentido amplo $\left(\mathrm{h}_{\mathrm{a}}{ }^{2}\right)$ foi elevada $(>0,80)$, situando-se acima das encontradas por Azevedo (2001), que estiveram entre 0,39 e 0,80, ao avaliar a resistência de PI 595201 ao PRSV-W. Em trabalho com Cucurbita moschata Duchesne, Oliveira et al. (2003) obtiveram herdabilidades no sentido amplo variando de 0,44 a 0,70 em avaliações de severidade de sintomas ao PRSV$\mathrm{W}$. Valores elevados de herdabilidade podem indicar que a característica em estudo está sob o controle de poucos loci. Conseqüentemente, a possibilidade de seleção de materiais resistentes ao WMV é alta.

$\mathrm{O}$ número de genes controlando a resistência de PI 595201 ao WMV foi de 4,16. A não-significância do modelo aditivo-dominante $\left(\chi^{2}=2,91\right)$ indicou ser esse o modelo adequado para explicar o controle do caráter, não necessitando da inclusão de interações epistáticas. A estimativa do grau médio de dominância (GMD) foi de 1,1869, sendo indicativo de dominância completa no sentido de maior resistência ao WMV. A distribuição de freqüências de fenótipos indica que a herança da resistência da introdução PI 595201 ao WMV parece ser de natureza oligo ou poligênica, devido à ausência de formação de classes fenotípicas discretas (dado não mostrado).

As estimativas de $\chi^{2}$ referentes ao teste de herança monogênica, foram significativas $(P 0,05)$ para todos os graus médios de dominância presumidos, indicando ser a resistência ao WMV controlada por mais de um gene (Figura 1). Resultados semelhantes quanto ao número de genes controlando resistência em cucurbitáceas foram encontrados. Maluf et al. (1997), estudando a herança da resistência ao PRSV-W em moranga (Cucurbita maxima), observaram que a resistência em ABL-10 e Redlands Trailblazer parece ser mediada por oligogenes e o mecanismo

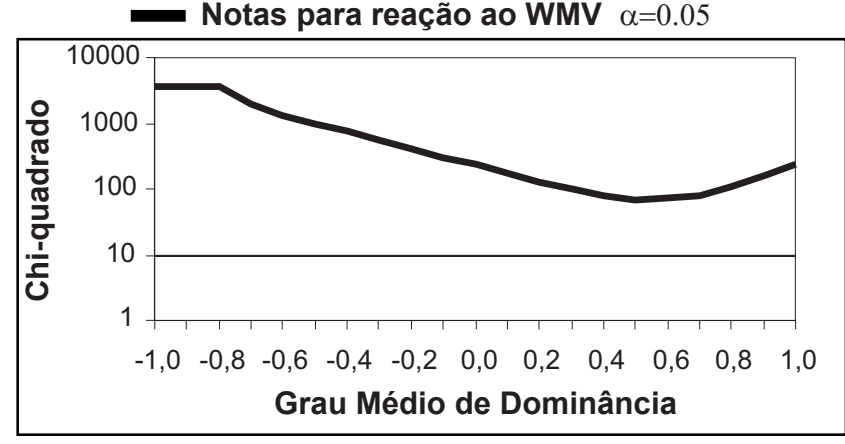

FIG. 1 - Teste da hipótese de herança monogênica sob diferentes graus médios de dominância para reação ao Watermelon mosaic virus em melancia (Citrullus lanatus).

de resistência do tipo tolerância. Azevedo (2001) estudando a herança da resistência ao PRSV-W na introdução PI 595201 de melancia, estimou o número de genes em 2,61. Dada à relação filogenética entre WMV e PRSV-W, ambos potyvírus, poder-se-ia especular sobre a possível relação de alelismo entre os genes que controlam resistência a ambos os vírus.

Os resultados dos testes de herança, feitos pelo teste da máxima verossimilhança, estão apresentados na Tabela 1. Comparando o modelo 1 com o modelo 5, que confronta a existência de um gene de efeito maior mais poligenes contra

TABELA 1 - Testes de hipótese de herança monogênica por meio da função de máxima verossimilhança para resistência ao Watermelon mosaic virus em melancia (Citrullus lanatus)

\begin{tabular}{crcc}
\hline \hline Modelos & ${ }_{c}^{2}$ & Graus de liberdade & Probabilidade \\
\hline 1 vs. 2 & 200,9296 & 3 & 0,000000 \\
1 vs. 3 & 109,5497 & 1 & 0,000000 \\
1 vs. 4 & 211,8506 & 4 & 0,000000 \\
1 vs. 5 & 109,6382 & 5 & 0,000000 \\
1 vs. 6 & 214,0593 & 6 & 0,000000 \\
1 vs. 7 & 124,1132 & 5 & 0,000000 \\
1 vs. 8 & 215,9205 & 6 & 0,000000 \\
1 vs. 9 & 462,3401 & 7 & 0,000001 \\
2 vs. 4 & 10,9209 & 1 & 0,000950 \\
2 vs. 6 & 13,1296 & 2 & 0,001409 \\
2 vs. 7 & $*$ & 2 & $*$ \\
2 vs. 8 & 14,9908 & 3 & 0,001824 \\
2 vs. 9 & 261,4104 & 4 & 0,000001 \\
3 vs. 5 & 0,0885 & 1 & 0,766052 \\
3 vs. 6 & 104,5095 & 4 & 0,000000 \\
3 vs. 8 & 106,3708 & 5 & 0,000000 \\
3 vs. 9 & 352,7904 & 6 & 0,000001 \\
4 vs. 6 & 2,2086 & 1 & 0,137238 \\
4 vs. 8 & 4,0698 & 2 & 0,130688 \\
4 vs. 9 & 250,4894 & 3 & 0,000000 \\
5 vs. 6 & 104,4210 & 3 & 0,000000 \\
5 vs. 9 & 352,7018 & 5 & 0,000000 \\
6 vs. 9 & 248,2808 & 2 & 0,000000 \\
7 vs. 8 & 91,8073 & 1 & 0,000000 \\
7 vs. 9 & 338,2268 & 2 & 0,000000 \\
8 vs. 9 & 200,9296 & 1 & 0,000000 \\
\hline
\end{tabular}

* Valor negativo, provavelmente devido a problemas de convergência. 
a existência de apenas poligenes, rejeita-se a hipótese, portanto havendo evidência de que existe um gene de efeito maior. Comparando o modelo 1 com o modelo 7, que confronta a existência de um gene de efeito maior mais poligenes, com apenas um gene de efeito maior, rejeita-se $H_{0}$; logo, há evidência de efeitos poligênicos. Portanto, a existência de um gene de efeito maior com efeitos aditivo e de dominância, juntamente com poligenes, parece ser o modelo mais adequado para explicar a herança da resistência de PI 595201 ao WMV. Entretanto, essa metodologia não testou a hipótese da existência de mais de um gene de efeito maior, que não pode ser descartada. Os resultados obtidos pelo teste da função de máxima verossimilhança são compatíveis com os do teste do qui-quadrado de herança monogênica, onde ambas apontam para um controle oligo ou poligênico para a herança da resistência ao WMV em melancia.

A despeito de o controle genético da resistência ser oligo ou poligênico, isso não deve trazer dificuldades para a obtenção de cultivares comerciais de melancia com resistência ao WMV, uma vez que a herdabilidade do caráter foi alta $(>0,80)$. De fato, linhagens avançadas resistentes ao WMV já foram obtidas a partir do cruzamento Crimson Sweet x PI 595201 (dados não mostrados).

\section{AGRADECIMENTOS}

Os autores agradecem ao CNPq e à CAPES pela concessão de bolsas.

\section{REFERÊNCIAS BIBLIOGRÁFICAS}

AZEVEDO, S.M. Herança da resistência ao vírus da mancha anelar do mamoeiro-estirpe melancia (PRSV-W) em melancia, Citrullus lanatus (Thunb.) Matsu. \& Nakai. (Tese de Doutorado) Lavras. Universidade Federal de Lavras. 2001.

CRUZ, E.S., PAZ, C.D., PIO-RIBEIRO, G., BATISTA, D.C., PEREIRA FILHO, G.G. \& ANDRADE, G.P. Levantamento de viroses em melancia e melão no Submédio São Francisco. Summa Phytopathologica 25:21. 1999.

CUCURBIT GENETICS COOPERATIVE. Release of Watermelon mosaic virus (WMV) resistant watermelon brindings lines WM-1,
WM-2, WM-3 and WM-4. Annual Report 19. 1996. p. 95.

FAUQUET, C.M., MAYO, M.A., MANILOFF, J., DESSELBERGER, U. \& BALL, L.A. Virus Taxonomy: Eighth Report of the International Committee on Taxonomy of Viruses. Academic Press. 2005.

MALUF, W.R., PEREIRA, J.J. \& FIGUEIRA, A.R. Inheritance of resistance to the Papaya ringspot virus-watermelon strain from two different accessions of winter squash Cucurbita maxima Duch. Euphytica 94:163-168. 1997.

MATHER, K. \& JINKS, J.L. Introduction to biometrical genetics. Ithaca NY. Cornell Univ. Press. 1977.

MOURA, M.C.C.L., LIMA, J.A.A., OLIVEIRA, V. B. \& GONÇALVES, M.F.B. Identificação sorológica de espécies de vírus que infectam cucurbitáceas em áreas produtoras do Maranhão. Fitopatologia Brasileira 26:90-92. 2001.

OLIVEIRA, A.C.B., MALUF, W.R., PINTO, J.E.B.P. \& AZEVEDO, S.M. Resistance to papaya ringspot virus in Cucurbita pepo L. introgressed from a interspecific C. pepo х C. moschata cross. Euphytica 132:211-215. 2003.

OLIVEIRA, V.B., LIMA, J.A.A., VALE, C.C. \& PAIVA, W.O. Caracterização biológica e sorológica de isolados de potyvirus obtidos de cucurbitáceas no Nordeste Brasileiro. Fitopatologia Brasileira 25:628-636. 2000.

RAMOS, N.F., LIMA, J.A.A. \& GONÇALVES, M.F.B. Efeitos da interação de potyvirus em híbridos de meloeiro, variedades de melancia e abobrinha. Fitopatologia Brasileira 28:199-203. 2003.

SHUKLA, D.D., WARD C.W. \& BRUNT, A.A. The Potyviridae. Wallingford. CAB International. 1994.

SILVA, W.P. Estimadores de máxima verossimilhança em misturas de densidades normais: Uma aplicação em genética. (Dissertação de Mestrado). Lavras. Universidade Federal de Lavras. 2003.

WRIGHT, S. The results of crosses between inbred strains of Guinea pigs, differing in number of digits. Genetics 19:537-551. 1934.

YUKI, V.A., REZENDE, J.A.M., KITAJIMA, E.W., BARROSO, P.V.A., KUNIYUKI, H., GROPPO, G.A., \& PAVAN, M.A. Occurrence, distribution, and relative incidence of five viruses infecting cucurbits in the State of São Paulo, Brazil. Plant Disease 84:516-520. 2000.

ZERBINI, F.M. \& MACIEL-ZAMBOLIM, E. A família Potyviridae - Parte II. Revisão Anual de Patologia de Plantas 8:225-265. 2000. 